\title{
Testosterone secretion by the isolated canine testis after controlled infusions of hCG
}

\author{
T. W. Boyden*, R. W. Pamenter and M. A. Silvert \\ Section of Endocrinology, Department of Internal Medicine and the Section of Urology, \\ Department of Surgery, University of Arizona College of Medicine, \\ Arizona Health Sciences Center, Tucson, Arizona 85724, and \\ *Veterans Administration Medical Center, Tucson, Arizona 85723, U.S.A.
}

\begin{abstract}
Summary. A technique is described for perfusion of isolated canine testes. Infusing the testes with various amounts of hCG identified a rate of $0.075 \mathrm{i} . \mathrm{u} . / \mathrm{min}$ as one which reliably increased testosterone secretion into the spermatic venous effluent without producing maximal testosterone production.
\end{abstract}

\section{Introduction}

The testes of dogs and men are similar in size and in their synthesis of steroids (Brinck-Johnsen \& Eik-Nes, 1957; Eik-Nes \& Hall, 1962; Folman, Haltmeyer \& Eik-Nes, 1972; Kelch, Jenner, Weinstein, Kaplan \& Grumbach, 1972; Tremblay et al., 1972). In 1957, Brinck-Johnsen \& Eik-Nes described methods for perfusing isolated dog testes and demonstrated increases in testosterone secretion following stimulation by pharmacological amounts of hCG. The rapid increase in hCG-stimulated testosterone secretion is the result of testosterone synthesis rather than release of stored hormone (Mason \& Samuels, 1961; Eik-Nes, 1962, 1975). The two preparations of Eik-Nes $(1964,1969)$ have several limitations: most experiments were performed using pharmacological amounts of hCG, dose-response curves for slower rates of infusion of hCG were not fully characterized, transfer of the testes to a metabolic chamber resulted in decreased gonadotrophic sensitivity and testicular viability was not examined at the conclusion of each perfusion. We have therefore characterized the normal hCG-stimulated testosterone production by the canine testis by using a method, modified from that of Eik-Nes $(1964,1969)$, of perfusing the isolated testis in vivo.

\section{Materials and Methods}

Adult male mongrel or greyhound dogs, weighing $25-35 \mathrm{~kg}$, were used. Most of the dogs were greyhounds because they are easier to obtain and have less subcutaneous fat. Anaesthesia was induced and maintained by intravenous injections of sodium pentobarbitone $(25-30 \mathrm{mg} / \mathrm{kg})$. An indwelling venous cannula connected to an isotonic saline solution $(9 \mathrm{~g} \mathrm{NaCl} / \mathrm{l})$ was placed in a foreleg vein and the dogs were laid supine. After surgically isolating the right femoral artery, a vertical incision was made parallel to the penis and extending from the external inguinal ring to the inferior portion of the symphysis pubis. Each spermatic cord was isolated by dissection and the testis was removed from the scrotum, thus allowing the gubernaculum to be severed. The testis was then reinserted into the scrotum. The processus vaginalis was opened and the 
cremasteric muscle fibres, the vas deferens and its vessels were divided and ligated completely, thus eliminating the possibility of cross circulation between the testes. Right and left spermatic arteries were separated from the cord structures by careful blunt dissection. Sodium heparin was injected in an initial amount of 300 units $/ \mathrm{kg}$ and throughout each experiment approximately 2000 units heparin/h in isotonic saline $(9 \mathrm{~g} \mathrm{NaCl} / 1)$ were continuously infused intravenously. The blood obtained from a polyethylene cannula in the femoral artery was used to perfuse the testes by means of a peristaltic pump (Sage Model 375A, Sage Instruments Division of Orion Research Inc., Cambridge, Massachusetts, U.S.A.).

The spermatic arteries were cannulated with polyethylene tubing (PE50) and attached to the pump with couplings that allowed for the infusion of hCG. At the time of cannulation each testis had an ischaemic period of less than 2 min. The spermatic veins were severed at the external inguinal ring and the venous effluent was collected with small plastic troughs leading into test tubes. In a number of experiments the veins were separated from the spermatic artery and cut before cannulation of the spermatic artery to determine the intrinsic rate of testicular blood flow. Testicular perfusions in these and subsequent experiments were established at the rate of the intrinsic blood flow. Our measured testicular blood flow in dogs was identical to the $1.9 \mathrm{ml} / \mathrm{min}$ / $10 \mathrm{~kg}$ body weight reported by Eik-Nes (1964). In a number of dogs intratesticular temperature was measured using a temperature probe (Y.S.I. model 41TJ, Yellow Springs Instrument Co., Yellow Springs, Ohio, U.S.A.). The temperatures remained at $36 \pm 1{ }^{\circ} \mathrm{C}$ during the $120-210 \mathrm{~min}$ perfusions.

The hCG (Sigma Chemical Corp., St. Louis, Missouri, U.S.A.) was infused into a testicular artery using a syringe pump (Sage Model 355 , Sage Instruments) at a rate of $0.083 \mathrm{ml} / \mathrm{min}$, using the couplings immediately behind the arterial catheters as a point of entry. Blood samples were centrifuged at $4^{\circ} \mathrm{C}$ and the plasma samples were stored frozen until required for the assay of testosterone.

Testosterone was determined by radioimmunoassay after extracting the plasma samples with hexane:ethyl acetate $(9: 1 \mathrm{v} / \mathrm{v})$ according to the method of Furuyama, Mayes \& Nugent (1970), without additional purification. The antibody was supplied by $\operatorname{Dr} \mathrm{C}$. A. Nugent (University of Arizona Health Sciences Center, Tucson, Arizona, U.S.A.): $5 \alpha$-dihydrotestosterone was the principal cross-reacting steroid ( $30 \%$ cross-reactivity) but other $\mathrm{C}_{19}$ steroids were not checked. Sensitivity of the testosterone standard curve was 5-10 pg/tube. Commercially available programmes from Hewlett-Packard based on the radioimmunoassay data analysis programmes of Rodbard \& Lewald (1970) and Rodbard (1974) were used to calculate plasma concentrations of testosterone. Inter- and intra-assay variations were 15 and $9 \%$, respectively.

At the conclusion of each perfusion, a single pharmacological dose of 25 i.u. hCG was injected into the spermatic artery. The response to the injection was used to distinguish a negative response to the hCG infusion from a testis which was injured. Only results from those testes with a normal response to this bolus injection were analysed.

\section{Results}

The response of the testis to a single injection of hCG is shown in Text-fig. 1. Increased concentrations of testosterone were apparent within $10 \mathrm{~min}$ and a maximum 20 -fold increase above baseline values was seen at $60 \mathrm{~min}$, before levels declined thereafter.

Variable rates of hCG infusion were examined to identify a rate that reliably produced an increase in the spermatic vein testosterone concentration, but did not maximally stimulate the testis. The results of these preliminary trials are shown in Text-fig. 2. An hCG infusion at a rate of $0.075 \mathrm{i}$.u./min produced a substantial but submaximal response (Text-fig. 3 ): mean \pm s.e.m. 


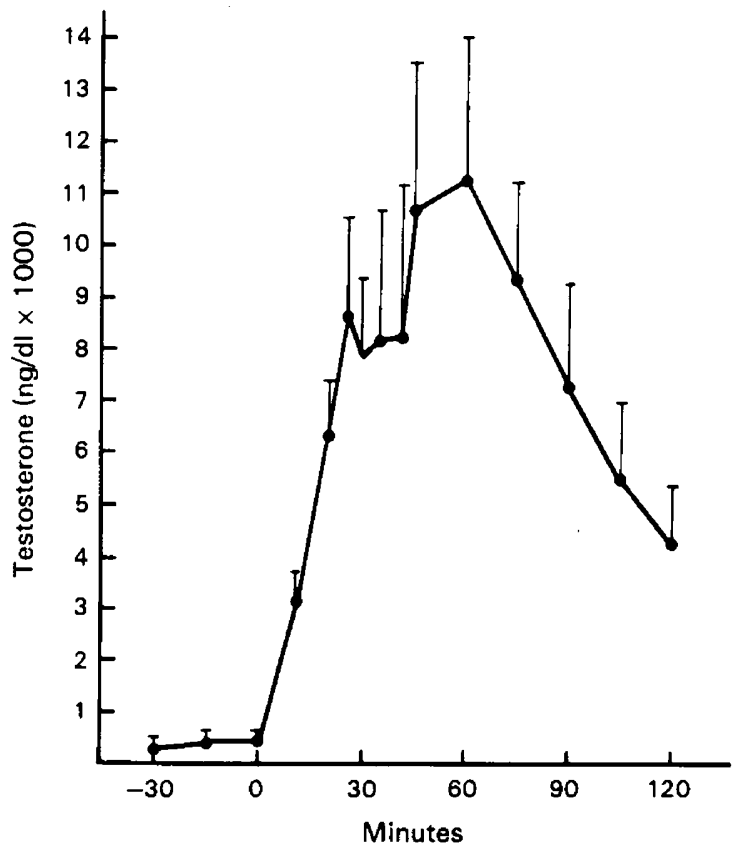

Text-fig. 1. Mean \pm s.e.m. $(N=5)$ concentrations of testosterone in the spermatic vein of the dog after injection of 25 i.u. hCG into the spermatic artery at time 0 .

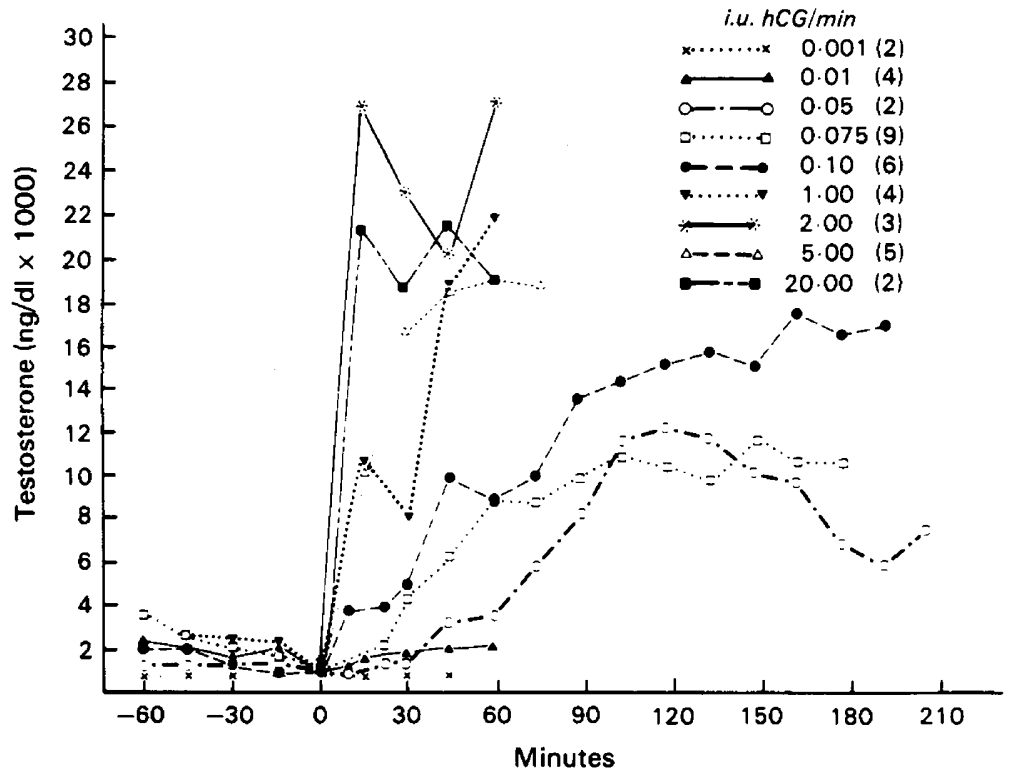

Text-fig. 2. Testosterone concentrations in the spermatic vein in response to infusion of hCG into the spermatic artery at different rates, starting at time 0 . Basal testosterone secretion during perfusion of the testis with blood only is indicated from -60 to $0 \mathrm{~min}$. The numbers in parentheses indicate the number of dogs examined at each dose. 


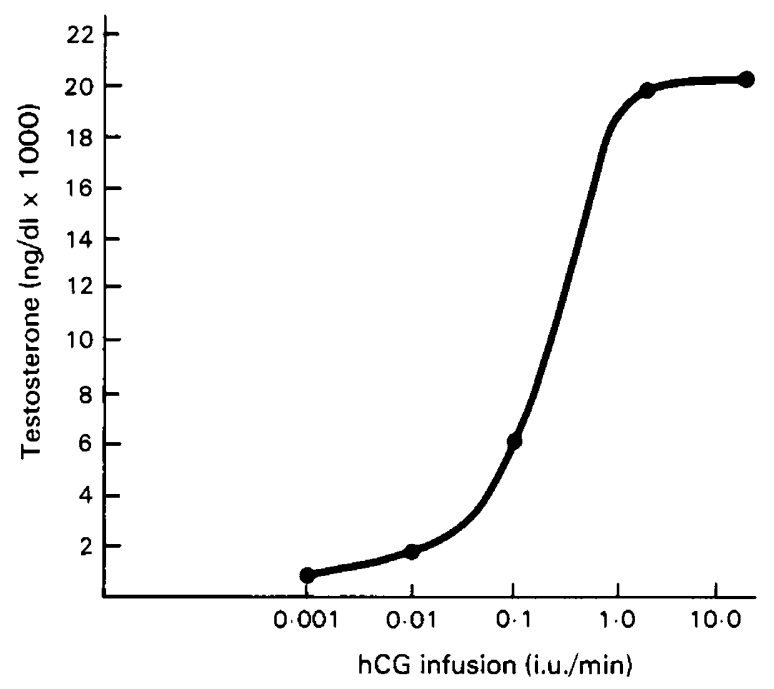

Text-fig. 3. Testosterone concentrations in the spermatic vein $45 \mathrm{~min}$ after the start of infusion with different doses of hCG.

basal spermatic vein testosterone concentrations were $844 \pm 172 \mathrm{ng} / \mathrm{dl}$ and increased to $3433 \pm$ $1100,8395 \pm 1050,9290 \pm 1872$, and $9211 \pm 1733 \mathrm{ng} / \mathrm{dl}$ at $45,90,120$ and $180 \mathrm{~min}$, respectively. Corresponding testosterone secretion rates calculated from the spermatic vein testosterone concentrations and the blood flow perfusing the testis were $48 \mathrm{ng} / \mathrm{min}$ in the basal state and $195,479,529$ and $525 \mathrm{ng} / \mathrm{min}$ at $45,90,120$ and $180 \mathrm{~min}$, respectively. Four of 64 testes did not respond to the 25 i.u. hCG injection at the end of the perfusion and the results of these perfusions were not further considered.

When hCG infusions at a rate of $0.075 \mathrm{i}$.u. $/ \mathrm{min}$ were stopped, spermatic vein testosterone concentration declined to basal levels in $60 \mathrm{~min}$ (Text-fig. 4).

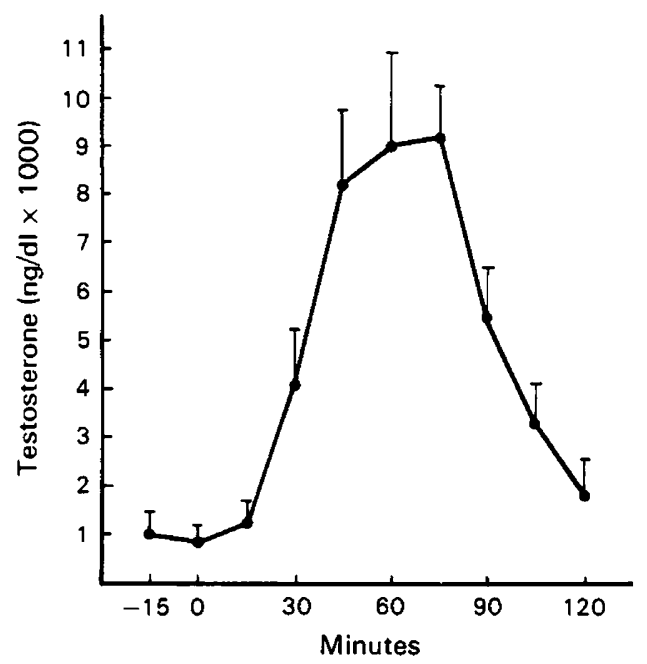

Text-6g. 4. Mean \pm s.e.m. $(N=4)$ testosterone concentrations in the spermatic vein before, during ( $0-60 \mathrm{~min})$ and after infusion of hCG at a rate of $0.075 \mathrm{i} . \mathrm{u} . / \mathrm{min}$. 


\section{Discussion}

Two methods for perfusing isolated canine testes were described by Eik-Nes $(1964,1969)$. In one preparation a single testis was used after cannulating its artery and vein, leaving the testis in the scrotum. The other preparation used both testes perfused in a metabolic chamber. In both preparations the testes were perfused with the animal's own blood delivered by a continuous infusion-withdrawal pump, and steroids in the venous effluent were measured by gas phase chromatography.

In our preparation both testes were used in each dog, after isolating their circulations and returning them to the scrotum. This avoids the decreased gonadotrophic sensitivity seen with the metabolic chamber preparation (Eik-Nes, 1971). A peristaltic pump was used to give a more reliable and physiological delivery of arterial blood since changes in the arterial supply to the testis have been shown to alter steroidogenesis (Tremblay et al., 1972). During our preliminary experiments the spermatic veins were catheterized with polyethylene tubing as described by EikNes (1964, 1969), and engorgement of the testis was observed when it was perfused at a rate equal to the measured intrinsic blood flow. In subsequent experiments plastic troughs were used to collect the venous effluent and testicular engorgement did not occur. Radioimmunoassay was used to measure testosterone rather than gas phase chromatography.

By performing all perfusions with the testis returned to the scrotum alterations in secretory function due to temperature changes were avoided. Using the animal's own blood for perfusion has obvious advantages over synthetic perfusion media and has been shown to result in greater testosterone secretion (Eik-Nes, 1967).

By selecting an hCG infusion rate that gave testosterone secretion responses in a physiological range, a model capable of identifying small changes in function has been developed. The data in Text-fig. 3 are expressed as a comparison of testosterone concentration after 45 min of the $\mathrm{hCG}$ infusion when different rates of infusion were used. This time was selected as one representing rapid increments in spermatic vein testosterone concentrations because lower infusion rates delayed the response curve and higher infusion rates rapidly resulted in a maximum response. The studies of Brinck-Johnsen \& Eik-Nes (1957), Mason \& Samuels (1961) and Eik-Nes $(1964,1969)$ used extremely large amounts of hCG to examine testosterone secretion. Eik-Nes (1967) did examine testicular testosterone secretion in response to hCG infusion rates as low as $0.4 \mathrm{i}$.u./min but maintained the experiment for only $15 \mathrm{~min}$. Moreover, the rates of hCG infusion were varied between 0.4 and $33 \mathrm{i} . \mathrm{u} . / \mathrm{min}$ and did not result in a graded dose response. The mean basal spermatic vein testosterone concentrations in this study were rather lower than the mean values reported by others but are well within the reported range of 484-24847 ng/dl (Folman et al., 1972; Tremblay et al., 1972). This difference in mean spermatic vein testosterone concentrations may be due to our predominant use of greyhound dogs rather than mongrels.

This work extends the observations of Eik-Nes $(1962,1964,1967,1969,1971)$ and demonstrates that the canine model described is a reliable means of examining testicular testosterone secretion. Since the right and left testis of the same animal produced similar amounts of testosterone (data not shown), a result that has been documented previously (Eik-Nes, 1971), this system could be used for comparing one hCG-stimulated testis with the contralateral testis infused with hCG plus other drugs or hormones. Chronic investigations can be performed by comparing perfused testicular secretion responses of one group of animals to the responses of a control group similar to that used in the present study.

\section{References}

Brinck-Johnsen, T. \& Eik-Nes, K.B. (1957) Effect of human chorionic gonadotropin on the secretion of testosterone and 4-androstene-3,17-dione by the canine testis. Endocrinology 61, 676-683. 
Elk-Nes, K.B. (1962) Secretion of testosterone in anesthetized dogs. Endocrinology 71, 101-106.

Eik-Nes, K.B. (1964) On the relationship between testicular blood flow and secretion of testosterone in anesthetized dogs stimulated with human chorionic gonadotrophin. Can. J. Physiol. Pharmac. 42, 671677.

Eik-Nes, K.B. (1967) Factors controlling the secretion of testicular steroids in the anaesthetised dog. J. Reprod. Fert., Suppl. 2, 125-141.

Eik-Nes, K.B. (1969) An effect of isoproterenol on rates of synthesis and secretion of testosterone. Am. J. Physiol. 217, 1764-1770.

Eik-Nes, K.B. (1971) Production and secretion of testicular steroids. Recent Prog. Horm. Res. 27, 517535.

Eik-Nes, K.B. (1975) Biosynthesis and secretion of testicular steroids. In Handbook of Physiology Section 7; Endocrinology, vol. 5, pp. 95-115. Eds R. O. Greep \& E. B. Astwood. Am. Physiol. Soc., Washington, D.C.

Eik-Nes, K.B. \& Hall, P.F. (1962) Isolation of dehydroepiandrosterone $-{ }^{14} \mathrm{C}$ from dogs infused with cholesterol ${ }^{14} \mathrm{C}$ by the spermatic artery. Proc. Soc. exp. Biol. Med. 111, 280-282.

Folman, Y., Haltmeyer, G.C. \& Eik-Nes, K.B. (1972)
Production and secretion of 5-dihydrotestosterone by the dog testis. Am. J. Physiol. 222, 653-656.

Furuyama, S. Mayes, D.M. \& Nugent, C.A. (1970) A radioimmunoassay for plasma testosterone. Steroids $16,415-428$.

Kelch, R.P., Jenner, M.R., Weinstein, R., Kaplan, S.L. \& Grumbach, M.M. (1972) Estradiol and testosterone secretion by human, simian, and canine testes, in males with hypogonadism and in male pseudohermaphrodites with the feminizing testes syndrome. J. clin. Invest. 51, 824-830.

Mason, N.R. \& Samuels, L.T. (1961) Incorporation of acetate- $1-{ }^{14} \mathrm{C}$ into testosterone and 3-hydroxysterols by the canine testis. Endocrinology 68, 899-907.

Rodbard, D. (1974) Statistical quality control and routine data processing for radioimmunoassays and immunoradiometric assays. Clin. Chem. 20, 12551270.

Rodbard, D. \& Lewald, J.E. (1970) Computer analysis of radioligand assay and radioimmunoassay data. Acta endocr., Copenh., Suppl. 147, 79-103.

Tremblay, R.R., Forest, M.G., Shalf, J., Martel, J.G., Kowarski, A. \& Migeon, C.J. (1972) Studies on the dynamics of plasma androgens and on the origin of dihydrotestosterone in dogs. Endocrinology $91,556-$ 561 .

Received 3 August 1979 